\title{
Numerical simulation of nonlinear oval-type vibration in cylindrical water storage tanks
}

\author{
A. Maekawa ${ }^{1} \&$ K. Fujita ${ }^{2}$ \\ ${ }^{1}$ Institute of Nuclear Safety System, Inc., Japan \\ ${ }^{2}$ Osaka City University \& Institute of Nuclear Safety System, Inc., Japan
}

\begin{abstract}
This paper describes the numerical simulation of nonlinear oval-type vibration in cylindrical water storage tanks. Oval-type vibration is a high-order vibration mode in the circumferential direction of the tank wall (axial wave number $m \geq 1$ and circumferential wave number $n \geq 2$ ). In our previous vibration experiment in which large excitation was applied to the base of a cylindrical water storage tank, the nonlinear behavior of oval-type vibration occurred. Under large excitation, nonlinear oval-type vibration with sub-harmonics of order one-half occurred, as well as oval-type vibration with fundamental harmonics. The nonlinear behavior of oval-type vibration was simulated by the numerical analysis method proposed in this paper, which allowed coupling analysis between the fluid and structure and large deformation analysis to be considered. The analysis results were compared with experiment results, and the analytical vibration behavior coincided with the experimental behavior. Accordingly, it was concluded that the proposed numerical analysis method could accurately simulate the experiment.
\end{abstract}

Keywords: numerical simulation, nonlinear vibration, oval-type vibration, subharmonics of order one-half, coupling analysis between fluid and structure, cylindrical water storage tank.

\section{Introduction}

It is well known that a coupled vibration system is formed between the tank structure and the contained water in cylindrical water storage tanks, causing complex vibration behavior (Shibata et al. [1]). In the coupled vibration system, the natural frequencies of both beam-type vibration (axial wave number $m \geq 1$ 
and circumferential wave number $n=1$ ), which is also called bending mode, and oval-type vibration (axial wave number $m \geq 1$ and circumferential wave number $n \geq 2$ ), which is also called shell mode, exist within the same frequency range due to coupling between the fluid and structure. Therefore, many vibration modes simultaneously occur when an excitation force such as earthquake motion is applied (Maekawa et al. [2]). Beam-type vibration has been studied by Veletsos et al. [3] and Fischer [4], whereas oval-type vibration has been studied by Chiba et al. [5], Amabili [6] and Fujita and Saito [7]. The studies have included theoretical studies on oval-type vibration modes based on shell theory and experimental studies on oval-type vibration modes caused by exciting the tank wall directly. However, there have been few studies on oval-type vibration indirectly caused by exciting the whole tank by using a shaking table. When taking into consideration that the excitation force such as earthquake motion vibrates the base of the tanks not the wall, oval-type vibration is indirectly excited generally. It is also important to reveal the nonlinear behavior of ovaltype vibration caused by such an excitation.

Maekawa et al. [2, 8] and Maekawa and Fujita [9, 10] have reported a series of studies on the vibration response of water storage tanks during earthquakes. Especially, they focused on the behavior of oval-type vibration when the base of the tank is excited. In their previous paper [10], nonlinear behavior of oval-type vibration was reported at large excitation. In this paper, numerical simulation of such nonlinear behavior is conducted by an analysis method that takes into consideration fluid-structure coupling and large deformation, and the validity of the simulation is discussed by comparison with experiments.

\section{Experiment}

\subsection{Test tank}

A photograph of the test tank used for the vibration experiment is shown in Fig. 1. The dimensions and shape of the tank as well as measuring locations are shown in Fig. 2. The cylindrical part was made of aluminum alloy, with a diameter of $900 \mathrm{~mm}$, height of 1,200 $\mathrm{mm}$ and thickness of $1 \mathrm{~mm}$. The upper and lower parts were fixed steel flanges. The tank was filled with water up to $95 \%$ (height of $1,140 \mathrm{~mm}$ ) Accelerometers and a laser displacement sensor were installed on the top of the tank to measure the response acceleration and displacement caused by beam-type vibration. Three laser displacement sensors were installed at heights of around $300 \mathrm{~mm}, 700 \mathrm{~mm}$ and $900 \mathrm{~mm}$ at the $0^{\circ}$ side of the cylinder to the response displacement caused by oval-type vibration. Some strain gauges were installed on the cylinder at the height of $700 \mathrm{~mm}$ to measure circumferential strain caused by oval-type vibration. The shape of the strain distribution represented the modes of oval-type vibration.

\subsection{Experimental method}

The base of the test tank was excited by using a shaking table. The excitation direction was horizontal between $0^{\circ}$ and $180^{\circ}$. Many kinds of input such as 
sinusoidal and beat waves with various magnitudes of acceleration were used in the experiment. In the sinusoidal excitation, $40 \mathrm{~Hz}$ was used as the excitation frequency.

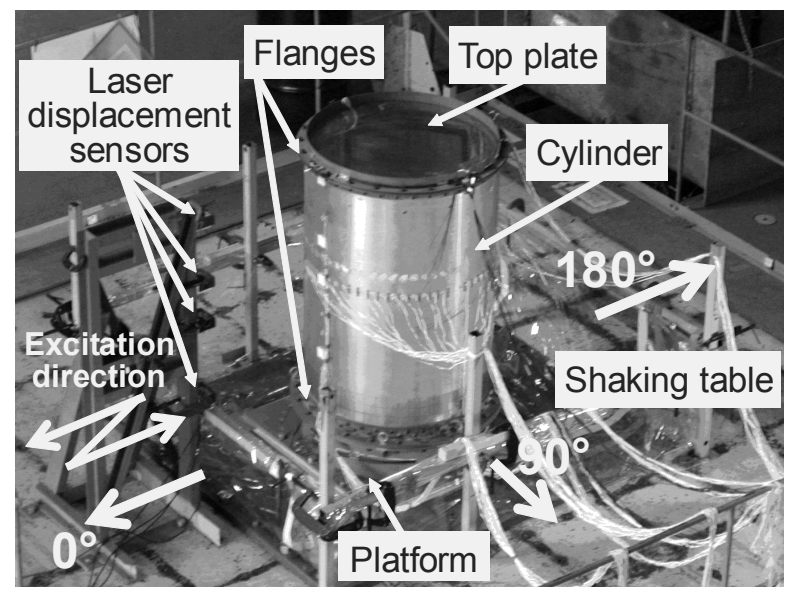

Figure 1: $\quad$ Test tank.

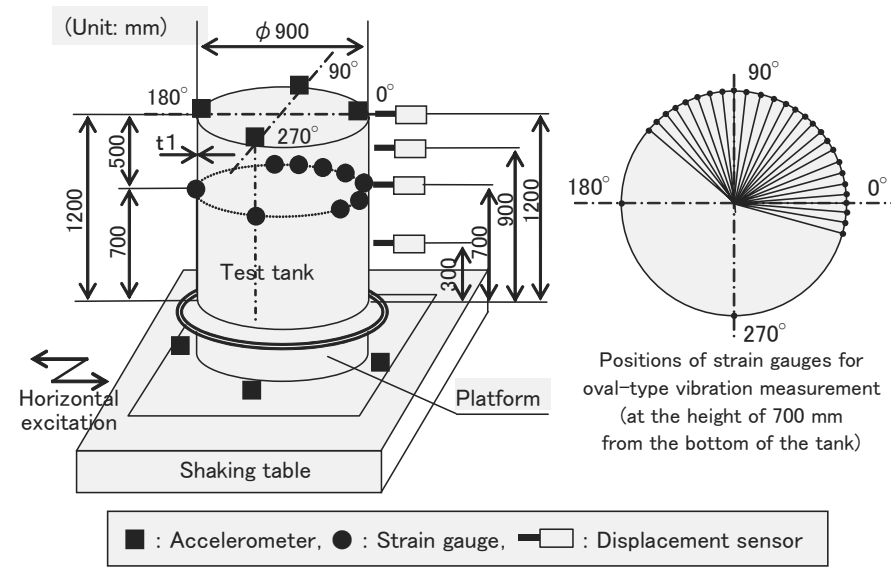

Figure 2: Dimensions and shape of the test tank and measuring points.

\section{Simulation}

\subsection{Analytical model for simulation}

The tank structure was three-dimensionally modeled by shell elements to simulate the behavior of oval-type vibration. Moreover, a shell element allowing geometric nonlinearity to be considered was applied to simulate a large 
amplitude caused by oval-type vibration. In this paper, the Belytschko-Lin-Tsay shell element (Belytschko et al. [11]), which can handle geometric nonlinearity and which has a four-node quadrilateral shell element with one-point quadrature in plane, was adopted. The element is based on the method of separating rigid body displacement and is generally used for finite displacement analysis. The contained water was modeled by a solid element to simulate the time history of liquid pressure and sloshing. A solid element, which complied with Euler's equation and had an eight-node hexahedral solid element with one-point quadrature, was applied for the fluid part including the gas phase. The water in the tank was assumed to be inviscid and incompressible. The gas phase over the free surface of the liquid is air and is treated as a void by making its density smaller. Coupling analysis between the fluid and structure had to be considered because the oval-type vibration was fluid-structure coupled vibration. The arbitrary Lagrangian Eulerian (ALE) method was used for the coupling analysis.

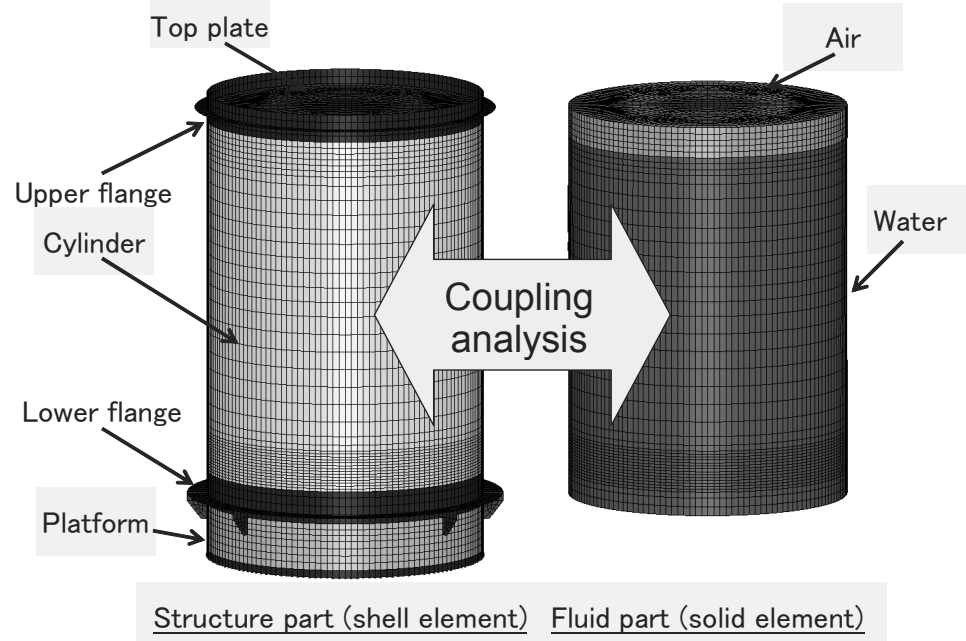

Figure 3: $\quad$ Analytical model.

Figure 3 shows the analytical model. The number of nodes was 67,526. The number of shell elements for the structural part was 11,944 and the number of solid elements for the fluid part was 60,016. Water properties were considered up to $95 \%$ of the height of the model and the void was set as the gas (air) phase for the remaining 5\%. Table 1 summarizes the material constants used for the analysis. The lower part of the platform and an arbitrary node were combined rigidly and the arbitrary node was excited. Vibration load was applied to the analytical model by moving the node forcibly. By giving the fluid part the velocity corresponding to movement of the structural part, the pressure change of water in the model was calculated. The balancing state was calculated in the first step of the analysis and then vibration analysis was conducted in the second step. A sinusoidal wave, which was increased or decreased in the front or end, was 
used as the input, in the same way as for the experiment. The excitation direction, excitation frequency and excitation acceleration were horizontal, 40 $\mathrm{Hz}$, and $2.0 \mathrm{G}$, respectively. The vibration response analysis was performed by the explicit integral method using the finite element code LS-DYNA.

Table 1: $\quad$ Material constants used for the analysis.

\begin{tabular}{|c|c|c|c|c|}
\hline & $\begin{array}{c}\text { Young's } \\
\text { modulus } \\
(\mathrm{MPa})\end{array}$ & $\begin{array}{c}\text { Poisson's } \\
\text { ratio }\end{array}$ & $\begin{array}{c}\text { Density } \\
\left(\mathrm{kg} / \mathrm{m}^{3}\right)\end{array}$ & $\begin{array}{c}\text { Bulk } \\
\text { modulus } \\
(\mathrm{MPa})\end{array}$ \\
\hline $\begin{array}{c}\text { Aluminum alloy } \\
\text { (cylinder) }\end{array}$ & 69,420 & 0.33 & 2,680 & - \\
\hline $\begin{array}{c}\text { Steel } \\
\text { (platform and } \\
\text { flange) }\end{array}$ & 203,000 & 0.3 & 7,800 & - \\
\hline $\begin{array}{c}\text { Polycarbonate } \\
\text { (top plate) }\end{array}$ & 1,960 & 0.3 & 1,190 & - \\
\hline $\begin{array}{c}\text { Water (in the tank) } \\
\text { (ingare }\end{array}$ & - & - & 1,000 & 2,200 \\
\hline
\end{tabular}

\subsection{Validity of the model}

Figure 4 shows the analytical deformation of the model. The deformation in the $90^{\circ}$ side of the model and the deformation in the cross section at the height of $700 \mathrm{~mm}$ are shown in Fig. 4(a) and Fig. 4(b), respectively. The scale factor is 20 to make it easy to grasp the shape. In Fig. 4(a), the analytical model leans a little, representing beam-type vibration. The deformation of the wall represents the occurrence of oval-type vibration because the wall is deformed by the amplitude of oval-type vibration.

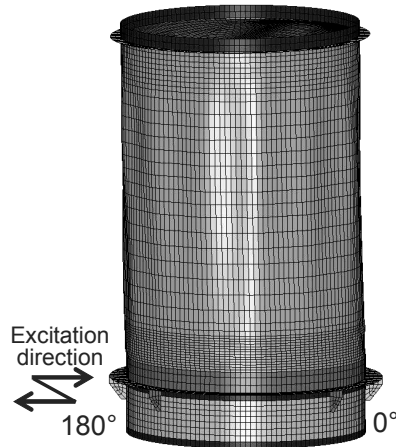

(a) Deformation in the $90^{\circ}$ side

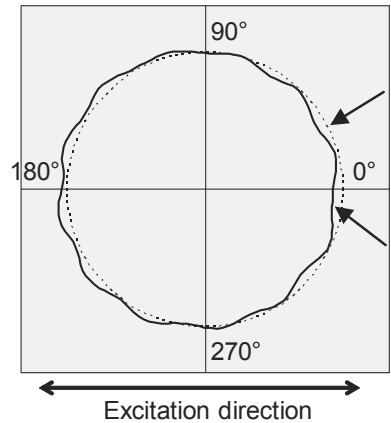

(b) Deformation at height of $700 \mathrm{~mm}$

Figure 4: Deformation view of the analytical model.

Figure 5 shows the distribution of liquid pressure. The vertical cross section between $0^{\circ}$ and $180^{\circ}$ is shown in Fig. 5(a) and the horizontal cross section at the 
height of $700 \mathrm{~mm}$ is shown in Fig. 5(b). The distribution of complex liquid pressure caused by the simultaneous occurrence of beam-type and oval-type vibrations was simulated in Fig. 5. The arrows in Fig. 4(b) and Fig. 5(b) show the locations where oval-type vibration occurred, indicating the same position. As shown in these figures, it is found that the deformation locations of the tank wall agree with the locations of local change of liquid pressure. This demonstrates that the ALE method for coupling analysis between fluid and structure is successfully applied to the vibration problem of cylindrical water storage tanks.

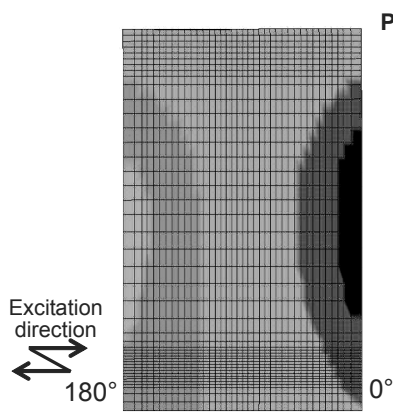

(a) Vertical cross section
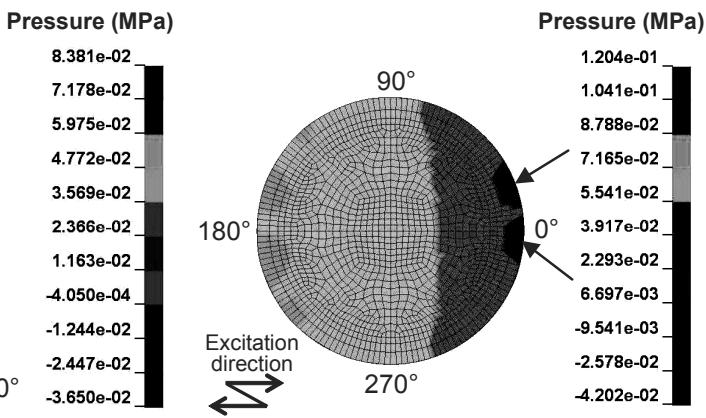

(b) Horizontal cross section at height of $700 \mathrm{~mm}$

Figure 5: Liquid pressure distribution.

\section{Comparison and discussion}

\subsection{Input for comparison}

Figure 6(a) shows the time history of the input used in the vibration experiment. It has a sinusoidal wave with excitation frequency of $40 \mathrm{~Hz}$. The input acceleration linearly increases with 20 waves, remains at the maximum steady state with $40 \mathrm{~Hz}$ for $1 \mathrm{sec}$, and then linearly decreases. Though the maximum acceleration of $2.0 \mathrm{G}$ was set in the shaking table controller as a target input, there actually was a little bit of fluctuation with time as shown in the figure. The analytical time history is shown in Fig. 6(b). It has a sinusoidal wave with

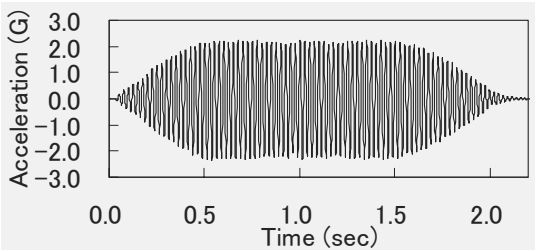

(a) experiment

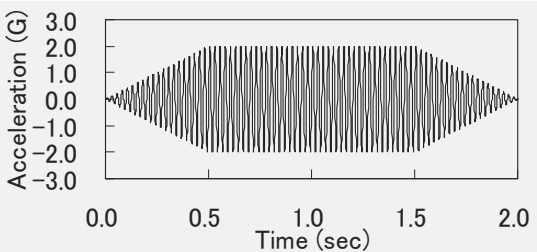

(b) simulation

Figure 6: Time histories of input acceleration. 
excitation frequency of $40 \mathrm{~Hz}$ and maximum acceleration of $2.0 \mathrm{G}$, with 40 waves being the steady state.

In the experiment, sinusoidal excitations with various magnitudes of acceleration were conducted, for example, $0.5 \mathrm{G}, 1.0 \mathrm{G}$ and $2.0 \mathrm{G}$ and so on. In addition, beat wave excitation was carried out [10] (results omitted here). Among them, the vibration response in the experiment with $2.0 \mathrm{G}$ showed remarkable nonlinearity, and is discussed below.

\subsection{Occurrence of nonlinear oval-type vibration}

Figure 7 shows the displacement of oval-type vibration under a large excitation of around 2 G. Figures 7(a), (b) and (c) show the time histories at the heights of $300 \mathrm{~mm}, 700 \mathrm{~mm}$ and $900 \mathrm{~mm}$, respectively. The maximum amplitude exceeds 1 mm-thickness of the tank wall, which is a deviation from the conditions assumed for small deformation theory. This suggests that geometric nonlinearity such as large deformation effects under large excitation should be considered. On the other hand, the periods of amplitude of oval-type vibration are different before/after the amplitude suddenly increases. Therefore, a frequency analysis for the time history of oval-type vibration in Fig. 7(b) was conducted. The results are shown in Fig. 8(b). In Fig. 8(b), oval-type vibration occurs at $40 \mathrm{~Hz}$ and 20 $\mathrm{Hz}$ for an excitation frequency of $40 \mathrm{~Hz}$. The oval-type vibration with $40 \mathrm{~Hz}$ is fundamental harmonics and is directly excited. $20 \mathrm{~Hz}$ is one half of the excitation frequency and shows the occurrence of oval-type vibration of sub-harmonics of order one-half. This oval-type vibration is called nonlinear oval-type vibration. In the frequency analysis, the peak of $20 \mathrm{~Hz}$ is larger than that of $40 \mathrm{~Hz}$, showing the dominant occurrence of nonlinear oval-type vibration. The experimental results revealed that nonlinear oval-type vibration of sub-harmonics of order one-half as well as oval-type vibration of fundamental harmonics occurs, namely that oval-type vibration is nonlinear when the tank is largely excited.

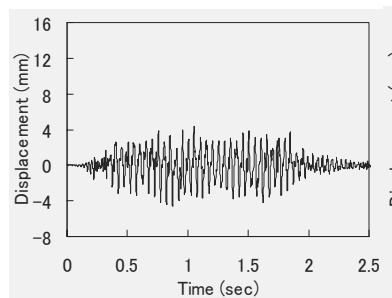

(a) 300mm-height

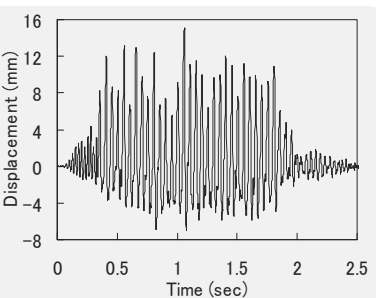

(b) $700 \mathrm{~mm}$-height

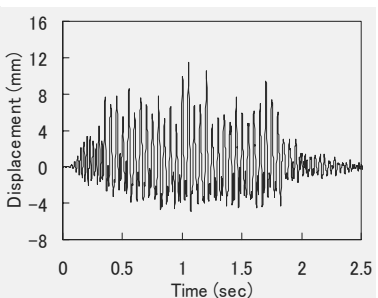

(c) $900 \mathrm{~mm}$-height

Figure 7: Time history displacement of oval-type vibration at various heights.

The numerical simulation proposed in this paper was conducted for the above experiment. The theory and procedure are described in section 3 . Figure 8 compares the analysis with the experiment. The time history of amplitude of oval-type vibration at the height of $700 \mathrm{~mm}$ of the analytical model is shown in Fig. 8(c). Comparing the experimental time history in Fig. 8(a), the magnitude of 
amplitude is only slightly different and the vibration characteristics are very similar during excitation. Namely, the amplitude suddenly increases and the periods change. Especially, comparing the response amplitude to the input amplitude in Fig. 6, the input acceleration of $2.0 \mathrm{G}$ may be a threshold for a change in the vibration characteristics of the response in Fig. 8. That is, the change is found to be caused when the input acceleration reaches $2.0 \mathrm{G}$. This is clear from the analysis as well as the experiment, and demonstrates the validity of the analytical method proposed in this paper.

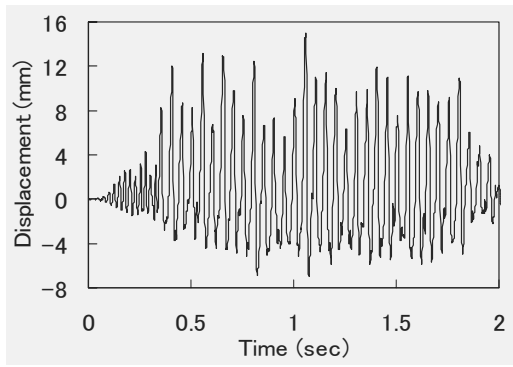

(a) Experimental time history

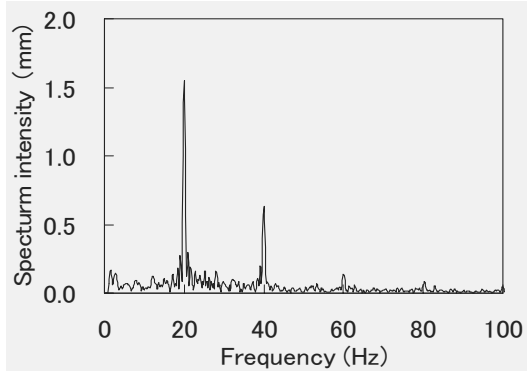

(b) Experimental frequency analysis

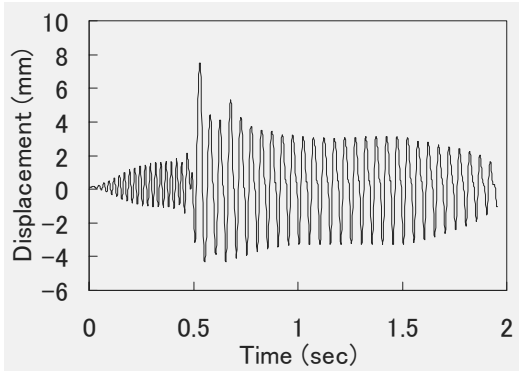

(c) Analytical time history

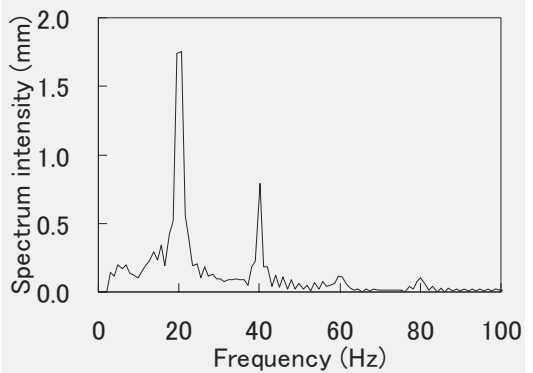

(d) Analytical frequency analysis

Figure 8: $\quad$ Experimental and analytical oval-type vibration behavior at 700 mm height.

The results of the experimental and analytical frequency analysis are shown in Fig. 8(b) and Fig. 8(d), respectively. In the analytical results in Fig. 8(d), there is a peak at $20 \mathrm{~Hz}$ as well as at $40 \mathrm{~Hz}$ for an excitation frequency of $40 \mathrm{~Hz}$. This shows the occurrence of nonlinear oval-type vibration of sub-harmonics of order one-half. Moreover, the nonlinear oval-type vibration is dominant because the peak of $20 \mathrm{~Hz}$ is larger than that of $40 \mathrm{~Hz}$. These results are the same as the experimental results, and so it is concluded that the numerical analysis method proposed in this paper can accurately simulate the nonlinear behavior of ovaltype vibration under large excitation.

\subsection{Identification of nonlinear oval-type vibration mode}

The mode of nonlinear oval-type vibration was identified by the shape of the circumferential strain distribution measured at the height of $700 \mathrm{~mm}$. The 
component of nonlinear oval-type vibration was extracted from the time history of circumferential strain, and then the shape of the distribution was decided by plotting the amplitude at the corresponding measuring position. The strain distribution in Fig. 9(a) has a petal-like appearance and represents the mode of nonlinear oval-type vibration. Based on the distribution in Fig. 9(a), the circumferential wave number $n=8$ was evaluated for nonlinear oval-type vibration of sub-harmonics of order one-half with $20 \mathrm{~Hz}$. Moreover, the axial half wave number $m=1$ was identified by comparing displacement amplitudes at all heights in Fig. 7.

The analytical results are shown in Fig. 9(b). This is the displacement amplitude of the wall caused by the nonlinear oval-type vibration at the height of $700 \mathrm{~mm}$ of the model. This represents the circumferential wave number, which from the figure is $n=8$. The axial half wave number $m=1$ is evaluated from the deformation of the analytical model in Fig. 4. Therefore, it is found that the analytical and experimental results are in good agreement regarding the mode of oval-type vibration. Namely, the analytical method proposed in this paper can accurately simulate the nonlinear behavior of oval-type vibration under large excitation.

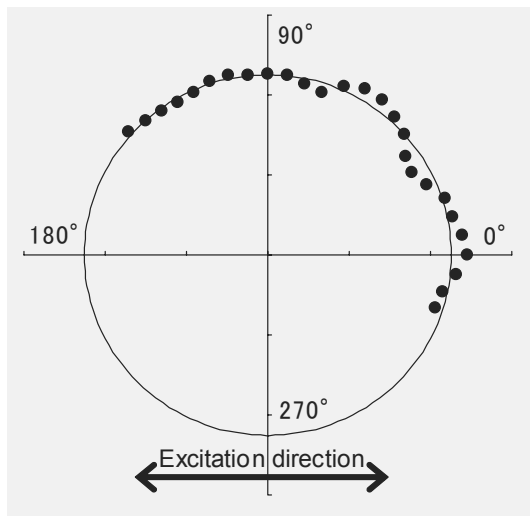

(a) Experiment

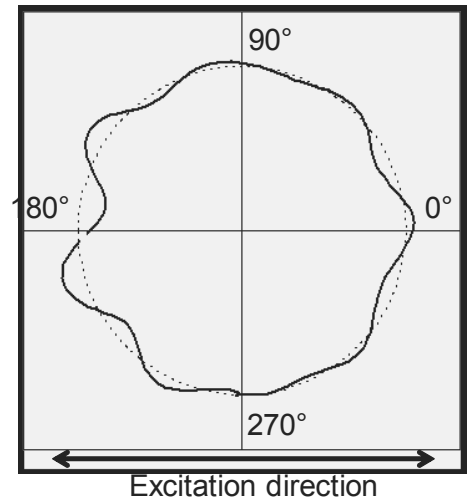

(b) Analysis

Figure 9: Experimental and analytical mode of nonlinear oval-type vibration.

\section{Conclusions}

The nonlinear behavior of oval-type vibration, which is a high-order vibration mode (axial wave number $m \geq 1$ and circumferential wave number $n \geq 2$ ) of cylindrical water storage tanks in the circumferential direction, was discussed. The nonlinear oval-type vibration behavior was accurately simulated by the numerical analysis method proposed in this paper. The analytical results are summarized as follows:

(1) The numerical simulation method, which allowed coupling analysis between the fluid and structure and large deformation analysis to be considered, could 
be applied to the vibration problem of cylindrical water storage tanks including the nonlinear behavior of oval-type vibration.

(2) The analysis method was verified by comparing analytical and experimental results. The analytical results showed that nonlinear oval-type vibrations of sub-harmonics of order one-half as well as oval-type vibration of fundamental harmonics occurred in the same way as in the vibration experiment. Especially, the analysis coincided with the experiment in terms of the time-history characteristics of nonlinear oval-type vibration and the vibration mode.

\section{References}

[1] Shibata, H., Shigeta, T., Kubota, M. \& Morikawa, S., On some results on response observation of liquid storage tanks to natural earthquakes, Proc. of ASME PVP Conf., ASME, Pittsburg, 77, pp. 21-28, 1988.

[2] Maekawa, A., Shimizu, Y., Suzuki, M. \& Fujita, K., Vibration test of 1/10 scale model of cylindrical water storage tank, Proc. of ASME PVP Conf., ASME, San Diego, 486-1, PVP2004-2911, pp. 107-117, 2004.

[3] Veletsos, A.S., ASCE, M. \& Yang, J.Y., Earthquake response of liquidstorage tanks, Proc. of $2^{\text {nd }}$ Eng. Mech. Specialty Conf., pp. 1-24, 1977.

[4] Fischer, D., Dynamic fluid effect in liquid-filled flexible cylindrical tanks, Earthquake Eng. and Structural Dynamics, 7, pp. 587-601, 1979.

[5] Chiba, M., Yamaki, N. \& Tani, J., Free vibration of a clamped-free circular cylindrical shell partially filled with liquid-Part I: Theoretical analysis, Thin-Walled Structure, 2, pp. 265-284, 1984.

[6] Amabili, M., Eigenvalue problems for vibrating structures coupled with quiescent fluids with free surface, J. Sound and Vibration, 231(1), pp. 7997, 2000.

[7] Fujita, K. \& Saito, A., Coupled vibration analysis of a cylindrical shell with liquid, piping and unaxisymmetric structures, Proc. of $6^{\text {th }}$ Biennial Conf. on Eng. System Design and Analysis, ASME, Istanbul, ESDA2002/APM-026, pp. 1-10, 2002.

[8] Maekawa, A, Suzuki, M. \& Fujita, K., Nonlinear vibration response of a cylindrical water storage tank caused by coupling effect between beam-type vibration and oval-type vibration-Part 1: Vibration experiment, Proc. of ASME PVP Conf., ASME, Vancouver, PVP2006-ICPVT-11-93261, pp. 1$10,2006$.

[9] Maekawa, A. \& Fujita, K., Coupling between beam-type vibration and oval-type vibration of a cylindrical water storage tank, Fluid Structure Interaction and Moving Boundary Problems IV, eds. Chakrabarti, S.K. \& Brebbia, C.A., WIT Press: Southampton, pp. 121-130, 2007.

[10] Maekawa, A. \& Fujita, K., Occurrence of nonlinear oval-type vibration under large sinusoidal excitation: Experiment, Proc. of ASME PVP Conf., ASME, San Antonio, PVP2007-26461, pp. 1-8, 2007.

[11] Belytschko, T., Lin, J.I. \& Tsay, C.S., Explicit algorithms for the nonlinear dynamics of shells, Computer Methods in Applied Dynamics and Eng., 42, pp. 225-251, 1984. 